\title{
慢性血栓塞栓性肺高血圧症（CTEPH）に対して肺動脈血栓内膜摘除術 （PEA）を施行した患者における静脈血栓塞栓症の検討
}

\author{
小林 由幸 ${ }^{1}$, 孟 真 $^{2}$, 阿賀健一郎 ${ }^{1}$, 橋山 $\quad$ 直樹 ${ }^{2}$, 根本 寛子 ${ }^{2}$, 島袋 伸洋 ${ }^{2}$, 益田 宗孝 ${ }^{3}$
}

○要 約：慢性血栓塞栓性肺高血圧症（CTEPH）の発症機序は不明で, 深部静脈血栓症（DVT）の既往 は約半数にしか認められない，われわれは，肺動脈血栓内膜摘除術（PEA）を施行した22例を対象に，病 歷, 臨床所見, 術前下肢静脈画像所見と, Jamieson分類について解析した，急性肺血栓塞栓症の既往は3 例, DVTの既往は11例にあった．PEA術前検査では13例（59.1\%）にDVTを認めた．DVTの既往がない11名 中5例にも DVTを認めており，22例中，計 16例（72.7\%）には，既往歴あるいは術前検査でDVTが存在して いた，また，DVT合併例16例のうち12例が，Jamieson分類1型であり，有意に多く見られた $(p=0.0327)$. PEA 手術患者に扔いて, 既往歴だけでなく, 術前検査でのDVT陽性例も含めると, 高い頻度でDVTが合併 していた．また，DVT合併と中枢型CTEPH発症の関連が示唆された。

索引用語：慢性血栓塞栓性肺高血圧症，肺動脈血栓内膜摘除術，深部静脈血栓症，肺血栓塞栓症，静脈血 栓塞栓症

静脈学 $2018 ; 29(2): 53-58$

はじめに

慢性血栓塞栓性肺高血圧症（chronic thromboembolic pulmonary hypertension; CTEPH）とは, 器質化した血 栓により肺動脈が閉塞し，肺血流分布ならびに肺循環 動態の異常が6カ月以上にわたって固定しているものの うち, さらに平均肺動脈圧が $25 \mathrm{mmHg}$ 以上の肺高血圧 を合併している例を指す ${ }^{1)}$. 重症例の生命予後は不良で あるが, 肺動脈血栓内膜摘除術 (pulmonary endarterectomy；PEA）を行うことによって, 症状, 血行動態拉よ び生命予後が改善することが報告されている22.

CTEPHの発症機序は依然として明らかではない。海 外では一般的に深部静脈血栓症 (deep vein thrombosis; DVT）に起因する急性肺血栓塞栓症（acute pulmonary

\footnotetext{
${ }^{1}$ 済生会横浜市南部病院心臟血管・呼吸器外科

${ }^{2}$ 横浜南共済病院心臟血管外科

${ }^{3}$ 横浜市立大学外科治療学

受付：2018年1月 15 日受理：2018年3月13日

doi: 10.7134/phlebol.18-01
}

\section{(cc) BY-NC-ND}

embolism；APE）からの移行を想定しているが，DVTの 既往は約半数にしかなく, さらに本邦では，海外と比べ APEの既往を持つものが少ないことから ${ }^{3,4)}$, 繰り返す 無症候性肺塞栓 ${ }^{5)}$ やHLA-B ${ }^{*} 5201^{6)}$, 炎症性機序 ${ }^{7)}$, 線 溶系異常 ${ }^{8)}$ の関与も議論されている.

今回われわれは，(1)静脈血栓塞栓症（venous thromboembolism; VTE) とCTEPH発症，(2)DVTの有無・血 栓部位と CTEPHの血栓部位との関連について検討し た.

\section{対象と方法}

横浜南共済病院心臓血管外科で, 2003年10月から 2016年10月までにPEAを施行した22例を対象とした。 DVT • APEを含む病歴, 臨床所見, 術前下肢静脈画像 所見と, 術中の肺動脈病変部位の分類である Jamieson 分類 ${ }^{9)}$ について解析した.

Jamieson分類は，PEAでの術中所見から肺動脈の閉 塞形態を表す分類法で, 中枢型から順に type I IV と なっている. type I : 主肺動脈や葉間動脈に壁在血栓が 存在している, 最も中枢型の症例, type II : 主肺動脈や 
葉間動脈に大きな壁在血栓はないが内膜肥厚（器質化血 栓）があるもの, type III：区域動脈から亜区域動脈にか けて内膜肥厚や器質化血栓が存在している症例である. type IVは細動脈病変で通常手術適応はない. Jamieson 分類が左右で異なる症例については，より中枢側の分類 に含めた。

周術期に全例に対して詳細な下肢静脈エコー検査を 行った，超音波診断装置は，主に 7.5〜 $12 \mathrm{MHz}$ プローベ を装着したLOGIQ E9（GEヘルスケア・ジャパン株式 会社, 東京都), またはAplio 500 (キャノンメデイカル システムズ株式会社，栃木県）を使用し，DVTの診断 基準は圧迫法で静脈が完全に圧排されないこと, カラー ドプラ法での陰影欠損とした. パルスドプラ法での深 部静脈逆流は参考所見とした. 新鮮血栓のみではなく エコー輝度の高い慢性期血栓，下肢静脈瘤などの表在 静脈病変の検索も行った。 なお, acute on chronicで発症 した重症1例については, 造影MDCT（Aquilion ONE/ ViSION Edition（キャノンメディカルシステムズ株式会 社, 栃木県)）で大腿深静脈にfilling defectが確認され, DVTと診断した。準緊急手術であったため, 手術前に 下肢静脈エコー検査を行うことができず，術後早期に施 行している.

統計処理にはEZR（自治医科大学附属埼玉医療セン ター, 埼玉県）を使用した ${ }^{10 ）}$. カテゴリー変数の検定 にはFisherの正確確率検定，連続変数の検定には対応の ない $t$ 検定もしくはWelchの検定を用い, $p<0.05$ を有意 差ありと判定した。

\section{結果}

男性 10 例, 女性 12 例. 年齢中央值 61 歳. 主要な術前 臨床所見を, 2011 年の厚生労働省の臨床調査個人票の 結果 $^{3)}$, ヨーロッパおよびカナダのレジストリの結果 ${ }^{4)}$
と比較して示す（Table 1)。厚生労働省の臨床調査個 人票の結果では $37.2 \%$ とAPEの既往を持つ症例が海外 (74.8\%) に比して少なく，当院でも，3例（13.6\%）の みであった。臨床的な DVTの既往は 11 例 $(50.0 \%)$ と, 海外 $(56.1 \%)$, 本邦 $(50.4 \%)$ の既報とほほ同様の結果 だった。

一方で, 術前エコーもしくはCTでは，22例中 13 例 にDVTを認めた。APEやDVTの既往はなかったが術 前にDVTを指摘された例が5例，逆に既往があっても 術前検査で指摘できなかった例が3例であり，合計する と，22例中 16例 $(72.7 \%)$ が, 経過中にDVTを合併し ていた（Fig.1）.

個々の症例で既往歴および術前検査を併せた際, DVTの近位端は，10例が近位型（下大静脈 1 例，腸骨 静脈 3 例, 大腿静脈 6 例, 膝窩静脈 1 例 $) ， 6$ 例 であった。静脈瘤は3例に認められたが, うち2例は DVT も合併しており, 静脈瘤単独の症例は1例のみで あった。

Jamieson分類とDVTの関連は, type I：13例（近位型

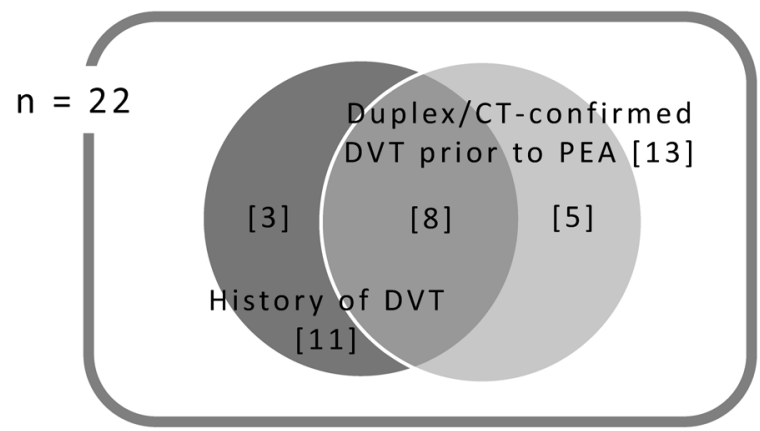

Fig. 1 Prevalence of deep vein thrombosis in patients with chronic thromboembolic pulmonary hypertension who underwent pulmonary endarterectomy.

Abbreviations: DVT, deep vein thrombosis; CT, computed tomography; PEA, pulmonary endarterectomy.

Table 1 Patient characteristics comparing Japanese and International registries

\begin{tabular}{lccc}
\hline & Current study $\mathrm{n}=22$ & Japanese registry ${ }^{3)} \mathrm{n}=519$ & International registry ${ }^{4)} \mathrm{n}=679$ \\
\hline Age, y, median [Q1; Q3] & $61[50 ; 67]$ & $67[53 ; 75]$ & $63[51 ; 72]$ \\
Gender, \% female & 54.5 & 71.9 & 49.9 \\
WHO class, \% I/II/III/IV & $0 / 18.1 / 54.5 / 27.3$ & $5.2 / 41.9 / 47.7 / 5.2$ & $0.7 / 17.8 / 68.6 / 12.8$ \\
Coagulopathies, \% & 13.6 & 11.7 & 31.9 \\
History of DVT, \% & 50.0 & 50.4 & 56.1 \\
History of APE, \% & 13.6 & 37.2 & 74.8 \\
mPAP, mmHg, median [Q1; Q3] & $42[39 ; 50]$ & $38[33 ; 46]$ & $47[38 ; 55]$ \\
PVR, dyn $\cdot \mathrm{cm}^{-5}$, median [Q1; Q3] & $656[507 ; 977]$ & $621[439 ; 916]$ & $709[480 ; 988]$ \\
\hline
\end{tabular}

Values are expressed as medians with first and third quartiles [Q1; Q3] or percentages. Abbreviations: DVT, deep vein thrombosis; APE, acute pulmonary embolism; mPAP, mean pulmonary arterial pressure; PVR, pulmonary vascular resistance. 
DVT 8例/遠位型DVT 4例/DVTなし1例), type II：7例 （近位型DVT 1例/遠位型DVT 2例/DVTなし4例）, type III：2例（近位型DVT 1例/DVTなし1例）であった。

DVTの有無による臨床病型の相違については (Table 2), DVT 非合併例は年齢が有意に高く，女性が 多い傾向が見られた。また，DVT非合併例にAPEの既 往を持つ者は見られなかった，DVT合併例では非合併 例に対し，Jamieson分類 type Iが有意に多く見られた。

DVTの部位による比較では（Table 3)，遠位型では DVT非合併例と同様，年齢が高く，女性が多い傾向が 見られたが，近位型との間に有意な差は見られなかっ た。

\section{考察}

肺血管床は線溶能が高く, 多くのAPEの肺動脈内 血栓は6カ月以内に完全に溶解されると報告されてき た ${ }^{11)}$ 。それに対し，CTEPH患者では，溶解されずに， 器質化した血栓が残存することで慢性的な肺動脈の狭窄 や閉塞をきたすとされているが，依然その詳細な発症機 序は不明である。 DVTの既往は 49.2 56.1\%程度 ${ }^{3,4,12)}$, APEの既往は，欧米では70.6 74.8\% ${ }^{4,12)}$ ，わが国で
$37.2 \%{ }^{3)}$, 本研究では $13.6 \%$ 程度であり, VTEの既往が ない患者も多くいることから, VTEの関与に懷疑的で, 「in situ thrombosis」や血管炎など他の機序を主張するグ ループも存在する ${ }^{7,13)}$.

しかしながら, Pengo ${ }^{14)}$ によって, VTEの既往が ない，初発で有症候性のAPE患者を追跡したところ 223 人のうち 7 人 $(3.8 \%)$ もがCTEPHに移行したことが報 告された。この研究に対し, 発症時にすでにCTEPHを 有している，いわゆる acute on chronicの病態が除外で きていないという批判はあるものの, Langらはこの結 果を受け,「CTEPH患者がVTEを基盤にもつことは, 疑いようがない」と述べている ${ }^{12)}$.

一方で先述の通り, とくに本邦では, 症候性の APE を伴わずに徐々に発症する潜在型が多く存在する ${ }^{3)}$. こ れら潜在型発症には, 無症候となりやすいDVT, とく に遠位型 $\mathrm{DVT}^{15)}$ からの繰り返しの血栓塞栓症 ${ }^{5)}$ が発症 の機序として考えられる，本邦では，臥位で症状の出に くい入院中の無症状患者を対象としたスクリーニング検 査で, 多くの遠位型血栓症が発見されている ${ }^{16)}$. VTE のハイリスクである周術期患者では，術後にスクリーニ ングを行うと，20.8から $65.3 \% に D V T か ゙$ 発見されるこ

Table 2 Comparison of clinical characteristics between DVT-positive and DVT-negative groups

\begin{tabular}{lccc}
\hline & DVT-positive $\mathrm{n}=16$ & DVT-negative $\mathrm{n}=6$ & $p$-value \\
\hline Age, y, median [Q1; Q3] & $53.5[47.5 ; 64.3]$ & $68[65 ; 71]$ & 0.0366 \\
Gender, female, $\%$ & 43.8 & 83.3 & 0.1619 \\
Coagulopathies, $\mathrm{n}$ & 3 & 0 & 1.0000 \\
History of APE, $\mathrm{n}$ & 4 & 0 & 1.0000 \\
mPAP, mmHg, median [Q1; Q3] & $47[41.5 ; 50.5]$ & $39.5[33.8 ; 41.5]$ & 0.1246 \\
PVR, dyn $\cdot \mathrm{s}^{-5}{ }^{-5}$, median [Q1; Q3] & $590[501 ; 770]$ & $917[773 ; 1069]$ & 0.4674 \\
WHO class, $\mathrm{n}$ I/II/III/IV & $0 / 3 / 7 / 6$ & $0 / 1 / 5 / 0$ & 0.185 \\
Jamieson classification, $\mathrm{n}$ 1/2/3 & $12 / 3 / 1$ & $1 / 4 / 1$ & $0.0327^{*}$ \\
\hline
\end{tabular}

Values are expressed as medians with first and third quartiles [Q1; Q3], n, or percentages. Abbreviations: DVT, deep vein thrombosis; APE, acute pulmonary embolism; mPAP, mean pulmonary arterial pressure; PVR, pulmonary vascular resistance. * type I versus type II+III.

Table 3 Comparison of clinical characteristics between proximal and distal DVT groups

\begin{tabular}{lccc}
\hline & Proximal DVT $\mathrm{n}=10$ & Distal DVT n=6 & $p$-value \\
\hline Age, $\mathrm{y}$, median [Q1; Q3] & $53[38 ; 64]$ & $61[55 ; 65.5]$ & 0.0708 \\
Gender, female, $\%$ & 43 & 66.7 & 0.3024 \\
Coagulopathies, $\mathrm{n}$ & 3 & 0 & 1.0000 \\
History of APE, $\mathrm{n}$ & 4 & 0 & 1.0000 \\
$\mathrm{mPAP}, \mathrm{mmHg}$, median [Q1; Q3] & $47[41.0 ; 51.0]$ & $44[42 ; 48.5]$ & 0.6792 \\
PVR, dyn· $\cdot \mathrm{cm}^{-5}$, median [Q1; Q3] & $590[507 ; 656]$ & $880[435 ; 986]$ & 0.4193 \\
WHO class, $\mathrm{n}$ I/II/III/IV & $0 / 2 / 4 / 4$ & $0 / 1 / 3 / 2$ & 1.0000 \\
Jamieson classification, n 1/2/3 & $8 / 1 / 1$ & $4 / 2 / 0$ & $0.703^{*}$ \\
\hline
\end{tabular}

Values are expressed as medians with first and third quartiles [Q1; Q3], n, or percentages. Abbreviations: DVT, deep vein thrombosis; APE, acute pulmonary embolism; mPAP, mean pulmonary arterial pressure; PVR, pulmonary vascular resistance. * type I versus type II+III. 
とが報告されているが，その多くは遠位型で無症候と考 えられる ${ }^{17-19)}$ 。またペースメーカーリードによる繰り 返しの無症候性PEが末梢型 CTEPHの発症に関与してい るとの報告もある ${ }^{20)}$ ，無症候性PEは， CT 検査の高性能 化で偶発的に数多く発見されるようになっているが21), これらが潜在型CTEPHの発症に関係している可能性も あり，今後の検討が必要である。

今回の研究では, 既往歴だけでなく, PEA術前の工 コー・CT陽性例も含めてみると, $72.7 \%$ という高い頻 度でDVTが合併していた．CTEPH患者においては，診 断から PEA術前まで抗凝固療法を受けているにも関わ らず，術前エコーもしくはCTで22例中13例にDVTを 認めていた，一方で，Markelらは，完全に血管を閉塞 させるようなDVTでも，エコー所見は 3 年で約半数が 正常化すると報告している ${ }^{22)}$ ．われわれの研究でも， VTEの既往がある患者11例中 3 例が術前には正常化し ていた。このことからも, 本研究で, 有症候性VTEの 既往がなく，かつ術前検査でもDVTの指摘がない患者 群も, 過去にDVTを起こしている可能性が否定できな い. 加えて, 慢性期のDVTは血栓退縮で発見しにくく, また，遠位型のDVTは，エコーでの描出が技術的に困 難で, 静脈造影と比較した感度は, 有症状患者で $73 \%$, 無症状患者では $53 \%$ と低い ${ }^{23)}$ 。これら慢性期DVTや遠 位型DVTが，エコー検査で見落とされてしまうことも 多いことを考慮に入れると, 本研究で示した頻度より多 くのCTEPH患者がDVTを合併していると考えてよい.

DVTの有無・部位とCTEPHの臨床病型についての 検討は，これまでに2件の報告があった，Jamiesonら ${ }^{24)}$ は，PEAを施行しJamieson分類type Iであった症例の 85.3\%に，DVTもしくはAPEの既往が見られ，type II， III群と比較し有意に多かった，と報告している。本研 究でも, DVT合併例 16例のうち 12 例 $(75.0 \%)$ が Jamieson分類type Iであり, DVT非合併例に対して有意に 多いという結果になった。

Kantakeら ${ }^{25)}$ は, CTEPH患者における，造影 CTで の肺動脈所見とDVTとの関連を検討している. Central disease scoreは, 左右上葉枝分岐前と下行枝の4箇所の うち, 血栓がある部位数の合計で, 中枢肺動脈病変の指 標と捉えることができる。またこの研究では，DVTの 頻度が低く，欧米とは異なった発症機序が想定されてい るHLA-B*5201の有無についても検討している，全例 での解析では, 有意差はなかったものの, HLA-B*5201 陰性例のサブグループ解析においては, 近位型DVTで, 有意に高い central disease scoreを示したと報告してお
り，近位型DVTと中枢型CTEPHの関連を示唆した。本 研究に掞いても, 近位型DVT群 10例のうち8例（80\%） がJamieson 分類type Iに該当していたが，限られた症例 数の今回の研究では, DVTの部位と Jamieson分類の関 係は明らかではなかった。

その一方で, 肺動脈内血栓の形態と肺高血圧の程度 には直接の相関はないとの報告もあり ${ }^{9,20,26)}$ ，末梢の肺 動脈に二次性の変化（リモデリング）が起こることが, 肺高血圧の進展に関与するとする「 small vessel disease」 という概念も導入されてきている ${ }^{27)}$. 病態のさらなる 解明を期待したい.

本研究の限界としては, retrospectiveな症例研究でか つ症例数が限られていること, 対象が CTEPH患者の中 でもPEAを行った患者に限られるため, 必然的に中枢 肺動脈病変の患者が多く含まれていることが挙げられ る。今後は, Balloon pulmonary angioplastyや, 内科的 治療が行われた患者の検討や比較も必要と考える.

\section{結語}

PEA手術患者において，既往歴だけでなく術前エ コー・CT陽性例も含めると, 高い頻度でDVTが合併し ていた。肢静脈画像検査の感度を考慮にいれると大多 数のCTEPHがVTEから発症している可能性が高いと考 えられる。また, 経過中のDVT合併の有無と, 中枢型 $\mathrm{CTEPH}$ 発症の関連が示唆された.

\section{利益相反}

なお，著者らには本論文について開示すべき COIはな い.

\section{付 記}

第24回 肺塞栓症研究会学術集会, 平成 29年11月, 東京.

\section{文献}

1) 中西宣文, 安藤太三, 植田初江, 他 : 循環器病の診断と治療に関 するガイドライン（2011年度合同研究班報告）。肺高血圧症治療 ガイドライン (2012年改訂版).http://www.j-circ.or.jp/guideline/ pdf/JCS2012_nakanishi_h.pdf

2) Delcroix M, Lang I, Pepke-Zaba J, et al: Long-term outcome of patients with chronic thromboembolic pulmonary hypertension: results from an international prospective registry. Circulation 2016; 133: 859-871

3) Tanabe N, Sugiura T, Tatsumi K: Recent progress in the diagnosis and management of chronic thromboembolic pulmonary hypertension. Respir Investig 2013; 51: 134-146 
4) Pepke-Zaba J, Delcroix M, Lang IM, et al: Chronic thromboembolic pulmonary hypertension (CTEPH): results from an international prospective registry. Circulation 2011; 124: 1973-1981

5) 呂 彩子, 景山則正, 谷藤隆信, 他：肺動脈内の器質化血栓の分 布からみた急性広範性肺血栓塞栓症. J Jpn Coll Angiol 2005; 45: 989-993

6) Tanabe N, Kimura A, Amano S, et al: Association of clinical features with HLA in chronic pulmonary thromboembolism. Eur Respir J 2005; 25: 131-138

7) Zabini D, Heinemann A, Foris V, et al: Comprehensive analysis of inflammatory markers in chronic thromboembolic pulmonary hypertension patients. Eur Respir J 2014; 44: 951-962

8) Morris TA, Marsh JJ, Chiles PG, et al: Fibrin derived from patients with chronic thromboembolic pulmonary hypertension is resistant to lysis. Am J Respir Crit Care Med 2006; 173: 1270-1275

9) Thistlethwaite PA, Mo M, Madani MM, et al: Operative classification of thromboembolic disease determines outcome after pulmonary endarterectomy. J Thorac Cardiovasc Surg 2002; 124: 1203-1211

10) Kanda $Y$ : Investigation of the freely available easy-to-use software "EZR" (Easy R) for medical statistics. Bone Marrow Transplant 2013; 48: 452-458

11) Menendez R, Nauffal D, Cremades MJ: Prognostic factors in restoration of pulmonary flow after submassive pulmonary embolism: a multiple regression analysis. Eur Respir J 1998; 11: 560-564

12) Lang IM, Madani MM: Update on chronic thromboembolic pulmonary hypertension. Circulation 2014; 130: 508-518

13) Egermayer P, Peacock AJ: Is pulmonary embolism a common cause of chronic pulmonary hypertension? Limitations of the embolic hypothesis. Eur Respir J 2000; 15: 440-448

14) Pengo V, Lensing AW, Prins $\mathrm{MH}$, et al: Incidence of chronic thromboembolic pulmonary hypertension after pulmonary embolism. $\mathrm{N}$ Engl J Med 2004; 350: 2257-2264

15) Rose SC, Zwiebel WJ, Miller FJ: Distribution of acute lower extremity deep venous thrombosis in symptomatic and asymptomatic patients: imaging implications. J Ultrasound Med 1994; 13: 243-250

16) 山田典一, 八巻 隆, 岩田博英: 本邦に扔ける下腿限局型深部静 脈血栓症に対する治療の現状（日本静脈学会サーベイ調査研究報

\section{告)。静脈学 $2013 ; 24: 211$}

17) Sakon M, Maehara $Y$, Yoshikawa $H$, et al: Incidence of venous thromboembolism following major abdominal surgery: a multi-center, prospective epidemiological study in Japan. J Thromb Haemost 2006; 4: 581-586

18) Fuji $T$, Ochi $T$, Niwa $S$, et al: Prevention of postoperative venous thromboembolism in Japanese patients undergoing total hip or knee arthroplasty: two randomized, double-blind, placebo-controlled studies with three dosage regimens of enoxaparin. J Orthop Sci 2008; 13: $442-451$

19) 冨士武史, 藤田 悟：股関節骨折手術施行後の静脈血栓塞栓症 の予防に対する fondaparinux sodiumの有用性. 骨折 2008; 30: 206-209

20) Madani MM, Auger WR, Pretorius V, et al: Pulmonary endarterectomy: recent changes in a single institution's experience of more than 2,700 patients. Ann Thorac Surg 2012; 94: 97-103; discussion, 103

21) Konstantinides SV, Torbicki A, Agnelli G, et al: 2014 ESC guidelines on the diagnosis and management of acute pulmonary embolism. Eur Heart J 2014; 35: 3033-3069, 3069a-3069k

22) Markel A, Meissner M, Manzo RA, et al: Deep venous thrombosis: rate of spontaneous lysis and thrombus extension. Int Angiol 2003; 22: $376-382$

23) Kearon C, Julian JA, Newman TE, et al: Noninvasive diagnosis of deep venous thrombosis. McMaster Diagnostic Imaging Practice Guidelines Initiative. Ann Intern Med 1998; 128: 663-677

24) Jamieson SW, Kapelanski DP: Pulmonary endarterectomy. Curr Probl Surg 2000; 37: 165-252

25) Kantake M, Tanabe N, Sugiura T, et al: Association of deep vein thrombosis type with clinical phenotype of chronic thromboembolic pulmonary hypertension. Int J Cardiol 2013; 165: 474-477

26) Azarian R, Wartski M, Collignon MA, et al: Lung perfusion scans and hemodynamics in acute and chronic pulmonary embolism. J Nucl Med 1997; 38: 980-983

27) Galiè N, Kim H: Pulmonary microvascular disease in chronic thromboembolic pulmonary hypertension. Proc Am Thorac Soc 2006; 3: $571-576$ 


\title{
Abstract \\ Venous Thromboembolism in Patients with Chronic Thromboembolic Pulmonary Hypertension Who Underwent Pulmonary Endarterectomy
}

\author{
Yoshiyuki Kobayashi ${ }^{1}$, Makoto $\mathrm{Mo}^{2}$, Kenichiro $\mathrm{Aga}^{1}$, Naoki Hashiyama ${ }^{2}$, Hiroko Nemoto ${ }^{2}$, \\ Nobuhiro Shimabukuro ${ }^{2}$, and Munetaka Masuda ${ }^{3}$ \\ ${ }^{1}$ Department of Cardiovascular and Respiratory Surgery, Saiseikai Yokohamashi Nanbu Hospital \\ ${ }^{2}$ Department of Cardiovascular Surgery, Yokohama Minami-Kyosai Hospital \\ ${ }^{3}$ Department of Surgery, Yokohama City University
}

Key words: chronic thromboembolic pulmonary hypertension, pulmonary endarterectomy, deep vein thrombosis, pulmonary embolism, venous thromboembolism

Background: Chronic thromboembolic pulmonary hypertension (CTEPH) is thought to be caused by unresolved acute pulmonary embolism (APE) arising from deep vein thrombosis (DVT). However, its pathophysiology is still unclear. Because significant numbers of patients with CTEPH have no history of APE or DVT, we investigated prevalence of venous thromboembolism and the lower extremity venous system in patients with CTEPH who had undergone pulmonary endarterectomy (PEA).

Methods: We retrospectively analyzed 22 consecutive patients (female, 54.5\%; median age, 61 years) who underwent PEA at Minami-Kyosai Hospital from October 2003 to October 2016. Patient medical histories including APE/ DVT, physical findings, and duplex ultrasonography or CT findings in lower extremities prior to PEA were analyzed. Surgical specimens were classified following the Jamieson classification.

Results: A history of APE was found in only 3 patients (13.6\%). Eleven (50.0\%) patients had an objectively confirmed history of DVT. Prior to PEA, duplex scan or CT identified DVT in 13 patients, despite 5 of them not having had a history of DVT. Although thrombi disappeared in 3 patients with a history of DVT, 16 (72.7\%) patients presented with DVT (proximal DVT, 10 patients; distal DVT, 6 patients) through the course of CTEPH. PEA surgical findings and their association with DVT sites were as follows. There were 13 Jamieson type I cases (proximal thrombi in pulmonary artery) comprising 8 cases of proximal DVT, 4 cases of distal DVT, and 1 case of no DVT; 7 Jamieson type II cases (intermediate type) comprising 1 case of proximal DVT, 2 cases of distal DVT, and 4 cases of no DVT; and 2 Jamieson type III cases (distal type) comprising 1 case of proximal DVT and 1 case of no DVT. Prevalence of Jamieson type I was significantly higher in the DVT-positive group than the DVT-negative group $(p=0.0327)$, although there were no significant relationships between DVT sites and pulmonary artery thrombi.

Conclusion: We found higher prevalence of DVT in patients with CTEPH than previously reported, possibly due to the use of meticulous duplex/CT scan examinations of DVT prior to PEA. Given the lower detection rate of chronic phase DVT using duplex scanning, most patients with CTEPH appeared to present leg venous pathology. In addition, we found that DVT was associated with proximal pulmonary artery lesions in CTEPH.

Jpn J Phlebol 2018; 29(2): 53-58 